\title{
Through-Thickness Variations of Deformed and Annealed Microstructures in ECAE-Processed Copper
}

\author{
O.V. MISHIN and J.R. BOWEN
}

DOI: $10.1007 / \mathrm{s} 11661-009-9970-6$

(C) The Minerals, Metals \& Materials Society and ASM International 2009

\section{Erratum to: METALLURGICAL AND MATERIALS \\ TRANSACTIONS A, Vol. 40A, No. 7, July 2009, \\ pp. 1684-92 \\ DOI: $10.1007 / \mathrm{s} 11661-009-9852-y$}

THE scale bars in Figures 4 and 7 in the original article were erroneously altered by the publisher. Following are the figures reflecting the correct scale bars:

O.V. MISHIN, Senior Scientist, is with the Center for Fundamental Research: Metal Structures in Four Dimensions, Materials Research Division, Risø National Laboratory for Sustainable Energy, Technical University of Denmark, DK-4000 Roskilde, Denmark. Contact e-mail: olmishin@lycos.com J.R. BOWEN, Senior Scientist, is with the Fuel Cells and Solid State Chemistry Division, Risø National Laboratory for Sustainable Energy, Technical University of Denmark. The online version of the original article can be found under doi: 10.1007/s11661-009-9852-y.

Article published online July 3, 2009 


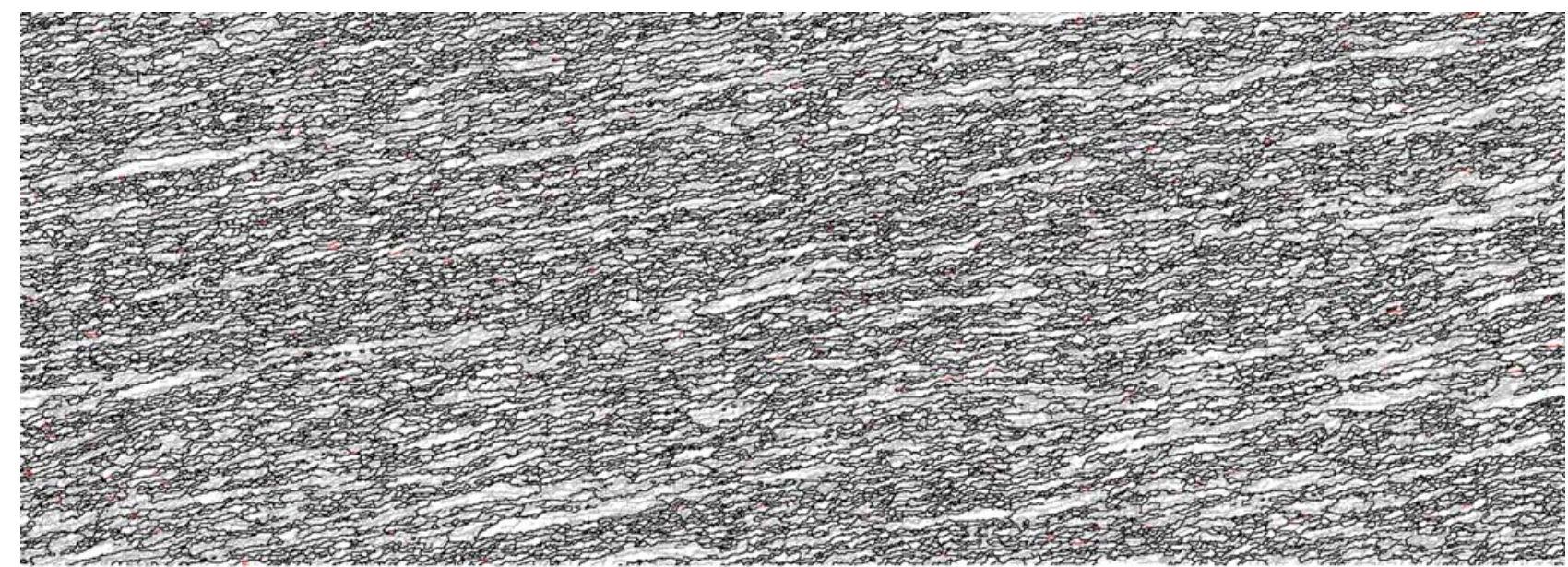

(a)

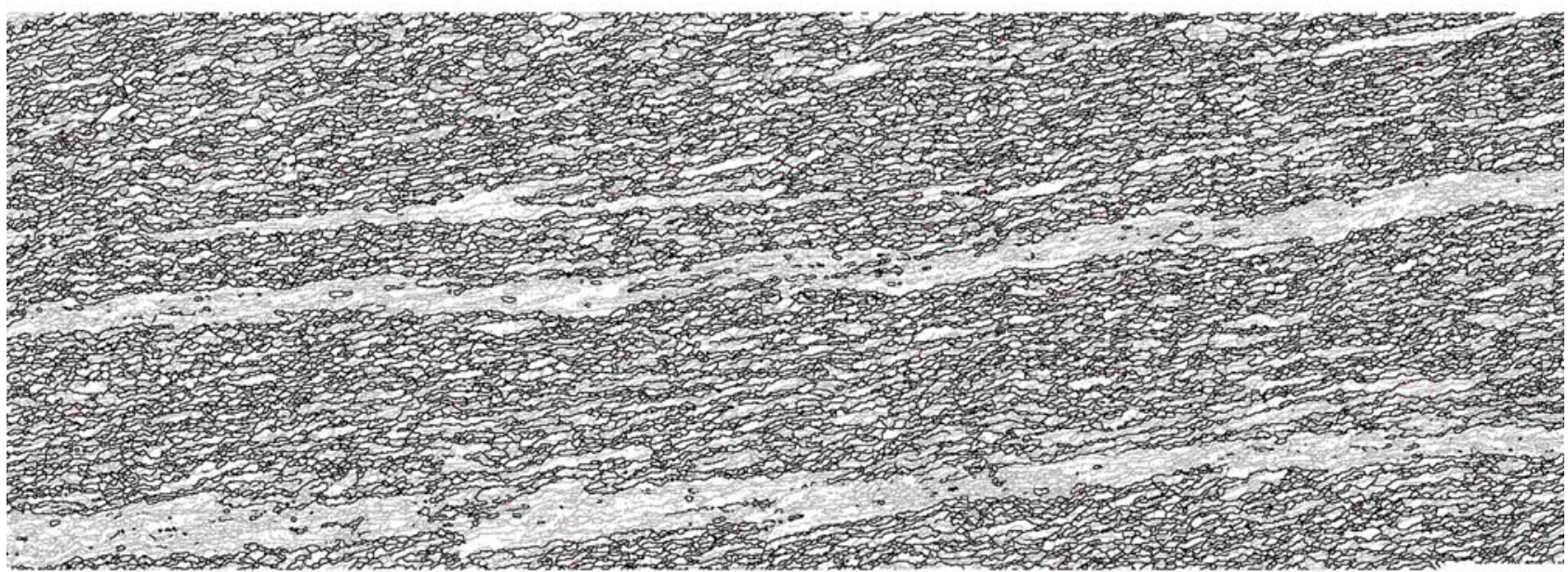

(b)

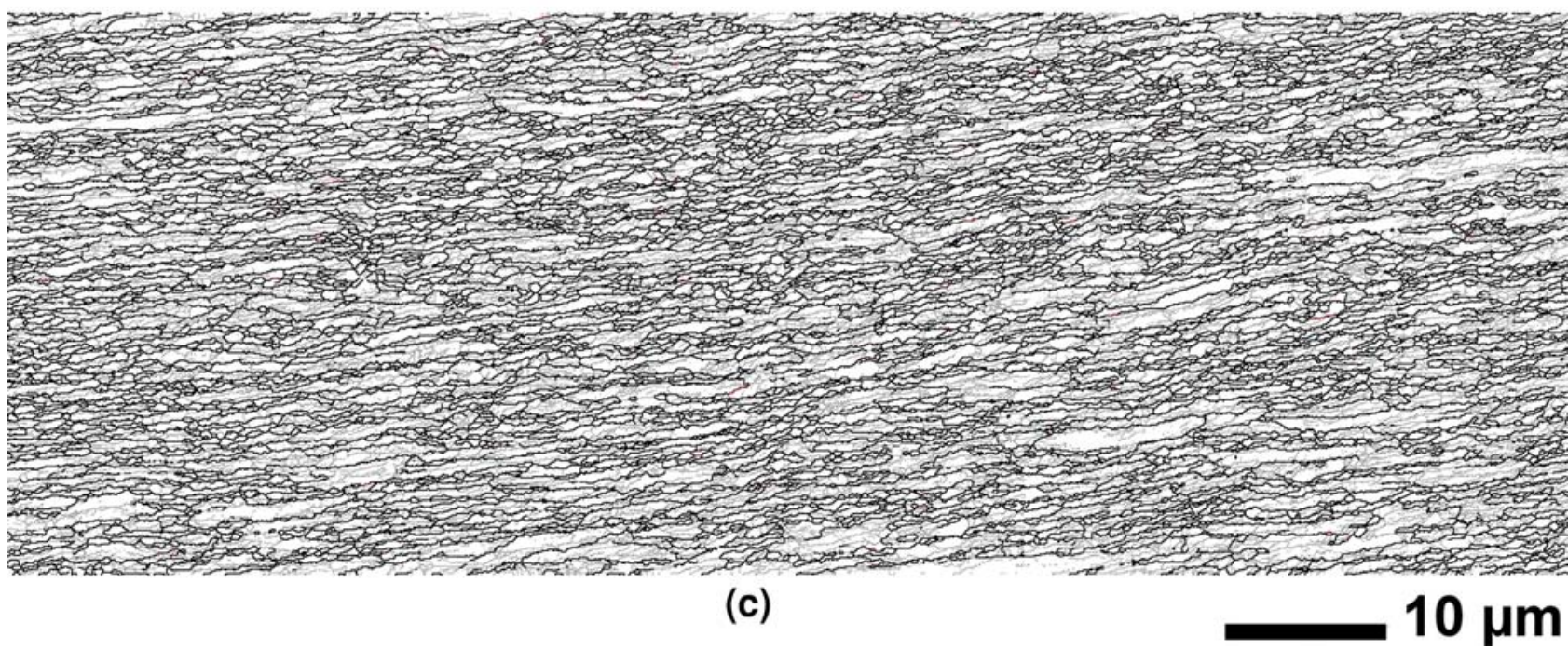

Fig. 4 -EBSD misorientation maps for the deformed sample: $(a)$ top, $(b)$ center, and $(c)$ bottom. HABs (>15 deg) are shown in black except for the twin boundaries shown in red. Misorientations 2 to 15 deg are shown as thin gray lines. The extrusion direction is parallel to the scale bar. 


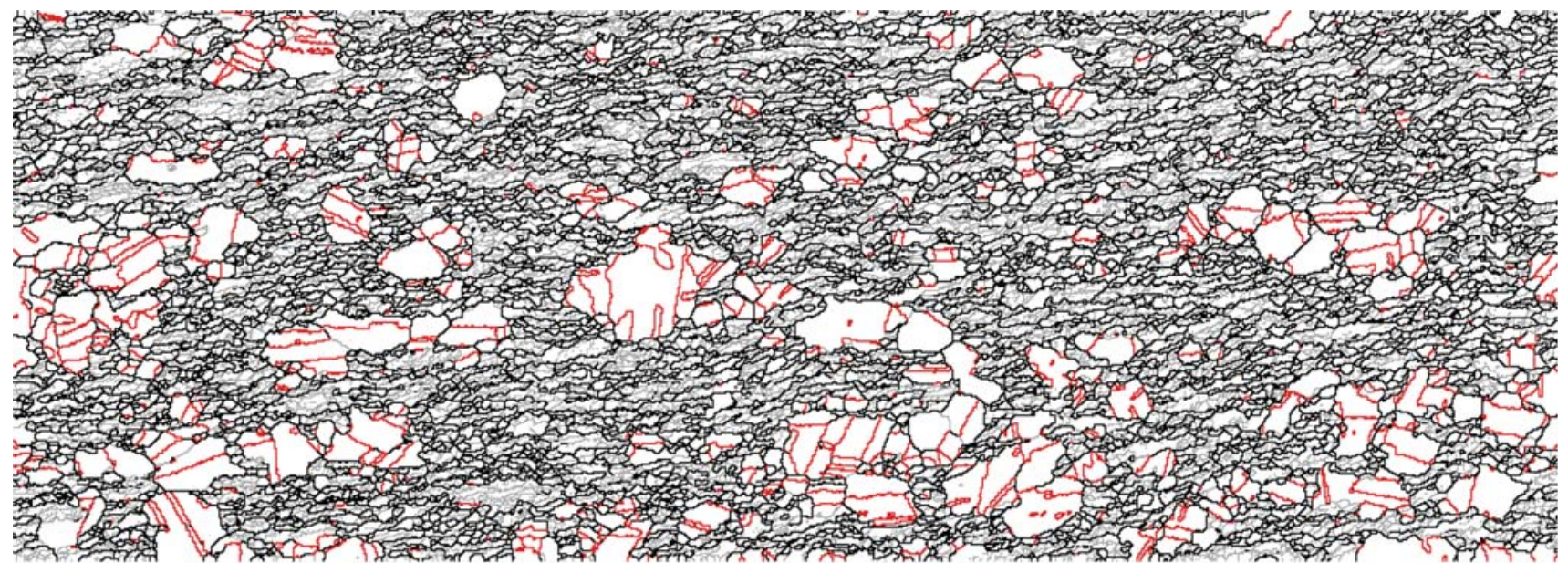

(a)

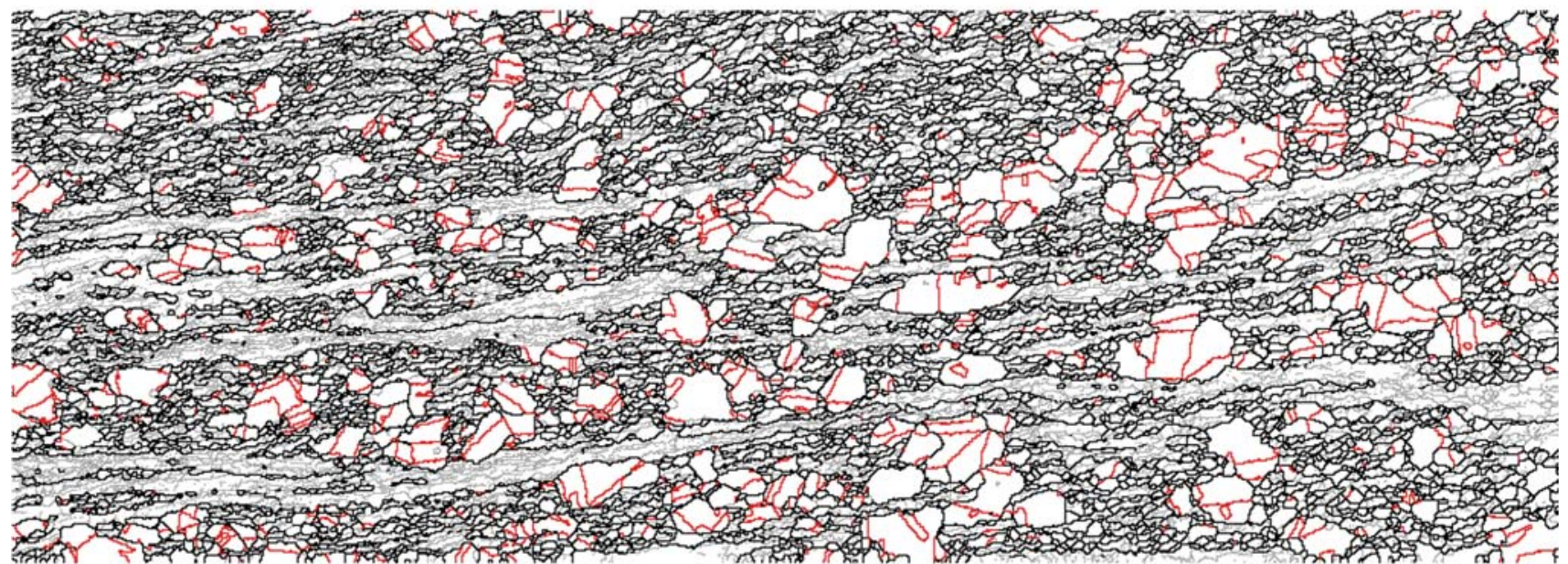

(b)

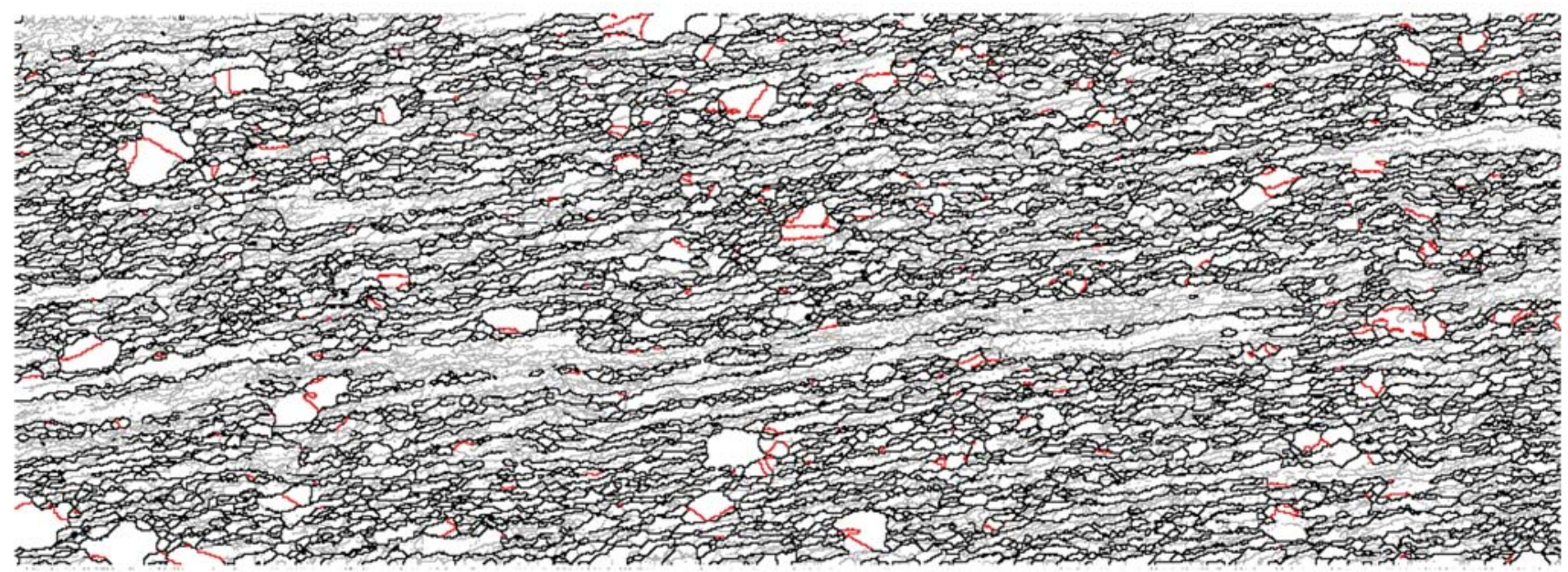

(c)

Fig. 7-EBSD misorientation maps for the partially recrystallized sample: $(a)$ top, $(b)$ center, and $(c)$ bottom. The HABs ( $>15$ deg) are shown in black, and twin boundaries are shown in red. Thin gray lines correspond to 2 to $15 \mathrm{deg}$ misorientations. The extrusion direction is parallel to the scale bar. 